\title{
micromachines
}

ISSN 2072-666X

www.mdpi.com/journal/micromachines

Article

\section{Researching the Aluminum Nitride Etching Process for Application in MEMS Resonators}

\author{
Jian Yang ${ }^{1,2}$, Chaowei Si ${ }^{1}$, Guowei Han ${ }^{1}$, Meng Zhang ${ }^{1}$, Liuhong Ma ${ }^{1}$, Yongmei Zhao ${ }^{1,2}$ and \\ Jin Ning ${ }^{1,2, *}$
}

1 Institute of Semiconductors, Chinese Academy of Sciences, Beijing 100083, China;

E-Mails: yangjian@semi.ac.cn (J.Y.); schw@semi.ac.cn (C.S.); hangw1984@semi.ac.cn (G.H.); zhangmeng@semi.ac.cn (M.Z.); maliuhong@semi.ac.cn (L.M.); ymzhao@semi.ac.cn (Y.Z.)

2 State Key Laboratory of Transducer Technology, Chinese Academy of Sciences, Beijing 100083, China

* Author to whom correspondence should be addressed; E-Mail: ningjin@semi.ac.cn;

Tel.: +86-10-8230-4492.

Academic Editor: Joost Lötters

Received: 12 October 2014 / Accepted: 6 February 2015 / Published: 16 February 2015

\begin{abstract}
We investigated the aluminum nitride etching process for MEMS resonators. The process is based on $\mathrm{Cl}_{2} / \mathrm{BCl}_{3} / \mathrm{Ar}$ gas chemistry in inductively coupled plasma system. The hard mask of $\mathrm{SiO}_{2}$ is used. The etching rate, selectivity, sidewall angle, bottom surface roughness and microtrench are studied as a function of the gas flow rate, bias power and chamber pressure. The relations among those parameters are reported and theoretical analyses are given. By optimizing the etching parameters, the bottom surface roughness of $1.98 \mathrm{~nm}$ and the sidewall angle of $83^{\circ}$ were achieved. This etching process can meet the manufacturing requirements of aluminum nitride MEMS resonator.
\end{abstract}

Keywords: aluminum nitride; micro-electro-mechanical-system; inductively coupled plasma etching

\section{Introduction}

Aluminum nitride (AIN) is an III-V group compound semiconductor material with the wide bandgap of $6.2 \mathrm{eV}$. The piezoelectric coefficient $d_{33}$ is about $5.5 \mathrm{pm} / \mathrm{V}$ and $d_{31}$ is about $-2.6 \mathrm{pm} / \mathrm{V}$ [1]. The excellent electromechanical properties make it suitable for MEMS resonators. The film bulk acoustic wave resonators (FBAR) are widely studied and used. The resonant frequency of $1.8 \mathrm{GHz}$ is achieved in 
FBAR [2]. Another type of resonator, the contour mode resonator (CMR), is becoming an important area of research, achieving more and more attention. The resonant frequency of CMR can be achieved as high as $10 \mathrm{GHz}$ [3]. In addition, the Lamb wave resonators play an important role in MEMS resonators. This has some special advantages, such as the low motional resistance, high frequency and the multiple frequency capability. More research has been done by Chih-Ming Lin et al. [4-6]. With the development of wireless communication technology, the resonators should have higher resonant frequency and a higher quality factor value.

Piezoelectric AlN MEMS resonators have a "sandwich" structure: the bottom electrode layer, AlN layer and the top electrode layer. The substrate of these types of resonators is typically $\mathrm{Si}$. In the manufacturing processes, the AlN etching is a key process. The etching result will strongly affect the performance parameters, such as resonant frequency and the quality factor. Recently, the inductively coupled plasma (ICP) etching process is widely used in the AlN etching process. However, there are still some problems in the process, such as poor sidewall angle, microtrenching effect and bottom roughness. Vladimir Bliznetsov et al. have done a lot of research in AIN etching. Their study shows the sidewall angle of $71.7^{\circ}$, the less obvious effects of microtrenching and the small bottom surface roughness of about 5-10 $\mathrm{nm}$ [7].

This paper focuses on the AlN etching process. The ICP etching technology was used. In this experiment, some major etching process parameters were studied. The etching results were characterized by the etching rate, selectivity, sidewall angle, bottom surface roughness and microtrenching.

\section{Experimental Section}

The etching sample in this experiment is polycrystalline AlN film with the thickness of $450 \mathrm{~nm}$ and the crystal orientation of (002). The full width of half maximum (FWHM) measured by X-ray diffraction is $1.7^{\circ}$ and the roughness root-mean-square (RMS) is $3.2 \mathrm{~nm}$ measured by atomic force microscope (AFM). The grain size value is approximately $50 \mathrm{~nm}$ measured by scanning electron microscope (SEM). The hard mask of $\mathrm{SiO}_{2}$ with the thickness of $1 \mu \mathrm{m}$ was used. In this paper, the selectivity is the etching rate ratio of $\mathrm{AlN}$ to $\mathrm{SiO}_{2}$. Chlorine-based gases were usually used in the etching process of $\mathrm{AlN}$ [8-12]. The etching products are a series of $\mathrm{Al}-\mathrm{Cl}$ volatile compounds, such as $\mathrm{AlCl}_{3}, \mathrm{Al}_{2} \mathrm{Cl}_{6}$ and other $\mathrm{Al}-\mathrm{Cl}$ compounds. In this experiment, the Sentech etcher was used and the etching gases are $\mathrm{Cl}_{2} / \mathrm{BCl}_{3} / \mathrm{Ar}$. In the etching gases, $\mathrm{BCl}_{3}$ was added to reduce the surface roughness. The initial process parameters are $\mathrm{Cl}_{2} / \mathrm{BCl}_{3} / \mathrm{Ar}=25 / 15 / 5 \mathrm{sccm}$, ICP source power of $700 \mathrm{~W}$, bias power of $80 \mathrm{~W}$ and chamber pressure of $0.5 \mathrm{~Pa}$. The single variability method was used in the experiment. That means that only one parameter is changed and the other parameters are fixed in each recipe. The results were measured by SEM and AFM.

\section{Results and Discussion}

\subsection{Etching Rate and Selectivity}

\subsection{1. $\mathrm{Cl}_{2}$ Flow Rate}

The etching rate and selectivity as a function of $\mathrm{Cl}_{2}$ flow rate are shown in Figure 1 . The etching rate increases with the $\mathrm{Cl}_{2}$ flow rate. The value of etching rate is $47 \mathrm{~nm} / \mathrm{min}$ when $\mathrm{Cl}_{2}$ flow rate is $20 \mathrm{sccm}$, 
whereas it increases to $110 \mathrm{~nm} / \mathrm{min}$ with $\mathrm{Cl}_{2}$ flow rate $40 \mathrm{sccm}$. When other process parameters are fixed, the concentration of $\mathrm{Cl}$ atom and ion will increase with the increase of $\mathrm{Cl}_{2}$ flow rate. As a result, the chemical reactive etch will be enhanced, which will increase the etching rate.

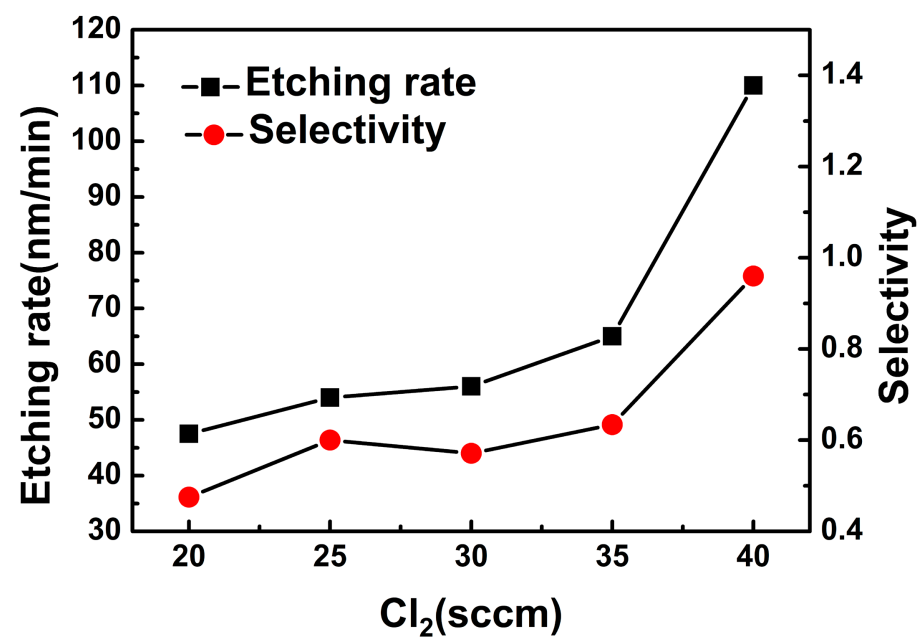

Figure 1. Aluminum nitride (AlN) etching rate and selectivity versus the flow rate of $\mathrm{Cl}_{2}$.

The selectivity increases with the $\mathrm{Cl}_{2}$ flow rate too. It has the same trend with the etching rate versus to $\mathrm{Cl}_{2}$ flow rate. The selectivity increases from 0.5 to 1 when $\mathrm{Cl}_{2}$ flow rate increases from 20 to $40 \mathrm{sccm}$. In the etching process, the etching mechanism can be divided into two species, namely the chemical reactive etching and the physical bombardment etching. When the $\mathrm{Cl}_{2}$ flow rate is increased, the main mechanism of the etching process starts to deviate from the physical bombardment etching to chemical reactive etching. As a result, the etching rate of $\mathrm{AlN}$ film becomes faster. Whereas the etching rate of $\mathrm{SiO}_{2}$ is mainly decided by the physical bombardment etching, the etching rate of $\mathrm{SiO}_{2}$ mask is approximately independent of $\mathrm{Cl}_{2}$ flow rate. Thus, the selectivity increases with the increase of $\mathrm{Cl}_{2}$ flow rate.

\subsubsection{Chamber Pressure}

Figure 2 presents the etching rate and selectivity as a function of the chamber pressure. We note that the etching rates are shifted positively when the pressure is lower than $0.9 \mathrm{~Pa}$, whereas negatively when it higher than $0.9 \mathrm{~Pa}$. The chamber pressure is determined by the rate of inlet gas flow and outlet gas flow. A higher chamber pressure leads to a higher gas concentration. Thus, the etching rate increases with the increasing concentration of $\mathrm{Cl}$ atom and ion. However, the etching rate will shift downward with the pressure increased further. There are three reasons for this phenomenon. (1) More collisions take place between the particles when the concentration is higher, which shortens the mean free path. The kinetic energy will decrease when the etching particles move to the surface of AlN film. This reason leads to a decreased etching rate. (2) More collisions lead to more recombination between the etchant ions and atoms. This recombination will generate more stable molecules. Hence, the concentration of the active etchant will decrease. (3) Due to the fixed rate of inlet gas flow, the outlet gas flow rate will decrease to meet the increase of chamber pressure. However, the etching products cannot be exhausted immediately. Some products will attach to the surface of AlN. The etching process will be suppressed to a certain extent. This also leads to the etching rate decreased. 


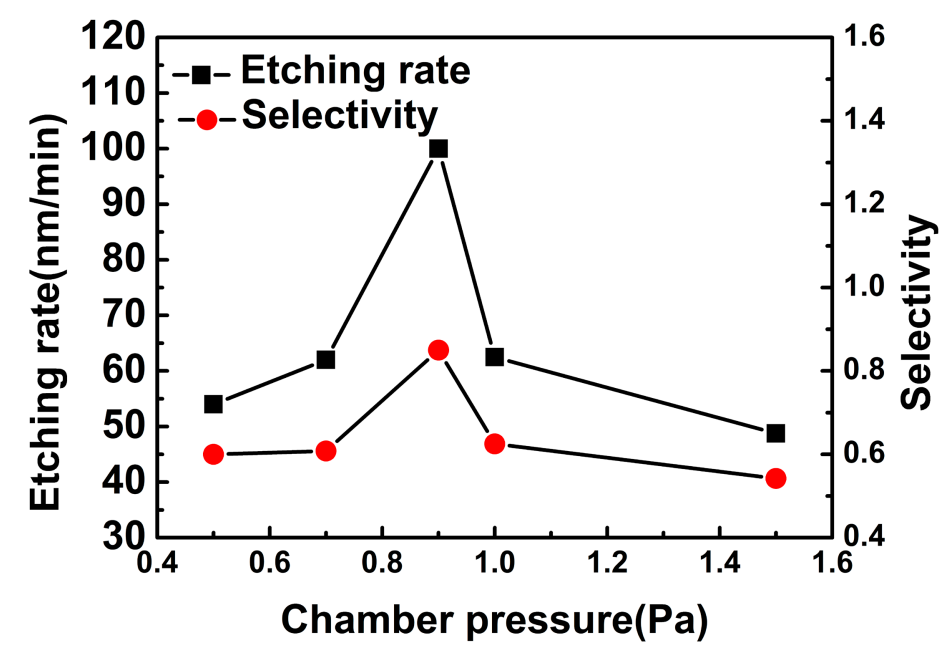

Figure 2. AlN etching rate and selectivity versus the chamber pressure.

\subsubsection{Bias Power}

The etching rate shows linearly increase with the bias power, as can be seen in Figure 3 . The etching rate increased from 47 to $64 \mathrm{~nm} / \mathrm{min}$ as the bias power was increased from 70 to $100 \mathrm{~W}$. The kinetic energy of the bombardment particles is mainly dominated by the bias power. In the plasma system, the ions are accelerated by the electric field which is generated by the bias power. When the bias power is increased, the kinetic energy of the ions will be increased. The physical bombardment etching will be enhanced. As a consequence, the etching rate will linearly increase with the bias power.

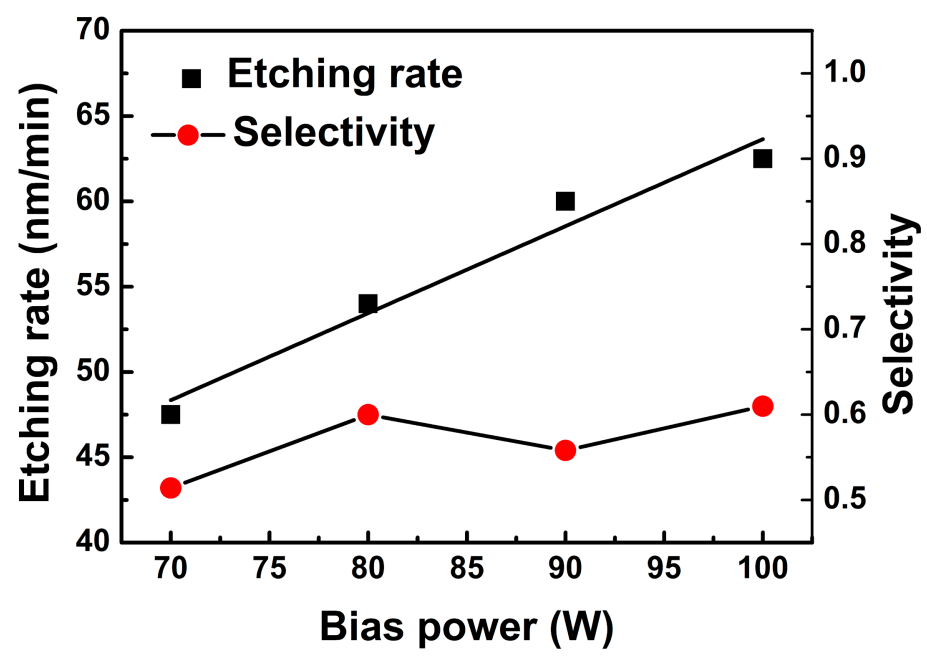

Figure 3. AlN etching rate and selectivity versus the bias power.

\subsection{4. $\mathrm{BCl}_{3}$ Flow Rate}

The etching rate and selectivity display a mixed effect with an increase of the flow rate of $\mathrm{BCl}_{3}$ as shown in Figure 4. However, the selectivity tends to a stable value with the further increase.

There is a positive correlation between the etching rate and the selectivity from the above Figures 1, 2 and 4. The reasons are analyzed as followed. In the etching process, the hard mask of $\mathrm{SiO}_{2}$ was etched mainly by physical bombardment etching. While AlN film was etched by both physical and chemical 
etching. When the chemical etching becomes the dominating mechanism, the etching rate of AlN is determined by the chemical etching. However, the etching rate of $\mathrm{SiO}_{2}$ is not obviously affected by the chemical etching. Thus, the selectivity has a positive correlation with etching rate.

However, the etching rate and selectivity do not exhibit a correlation if we only change the bias power. The main reason for this is that the physical etching mechanism will have an effect on both $\mathrm{SiO}_{2}$ and AlN etching rate. Both etching rates will be changed. Hence, there is no clear correlation between the etching rate and selectivity.

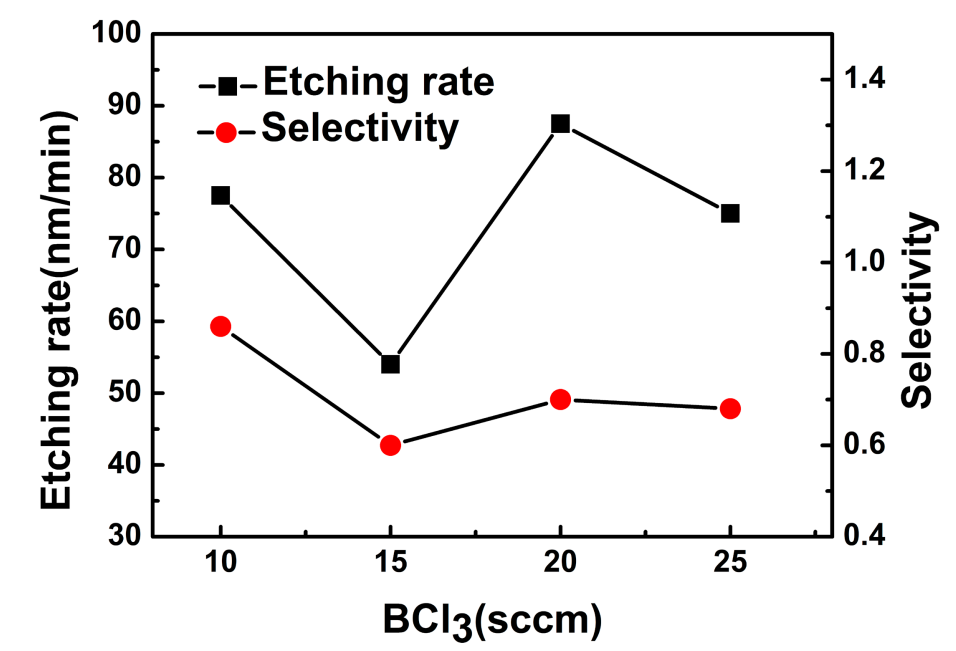

Figure 4. AlN etching rate and selectivity versus the flow rate of $\mathrm{BCl}_{3}$.

\subsection{Sidewall Angle and Roughness}

Figures 5 and 6 present the relation between the sidewall angle and the flow rate of $\mathrm{Cl}_{2}$ as well as $\mathrm{BCl}_{3}$. It decreases with the increasing flow rate, and shifts upward with the further increase. However, the surface roughness shows the opposite trend. With the increase of $\mathrm{Cl}_{2}$ or $\mathrm{BCl}_{3}$, the RMS values first increase and then decrease.

With the increase of $\mathrm{Cl}_{2}$ or $\mathrm{BCl}_{3}$ flow rate, the chemical etching becomes the main etching mechanism. The etching rates in grains and at the grain boundaries are different. Hence, the difference between the two etching rates is enlarged with increasing concentration of $\mathrm{Cl}$, which will lead to the increased surface roughness. However, the RMS trend turns to be decreased when the flow rate of $\mathrm{Cl}_{2}$ above $30 \mathrm{sccm}$ (or the $\mathrm{BCl}_{3}$ flow rate above $20 \mathrm{sccm}$ ). Large gas flow rates lead to more particle collisions in the chamber. As a result, the energy of $\mathrm{Cl}$ will be reduced. Therefore, the difference of the etching rates between the grain boundaries and the inside grains will be reduced. The RMS presents a downward trend.

The relation between the sidewall angle and the bias power is shown in Figure 7 . When the bias power is increased to $80 \mathrm{~W}$, the sidewall angle rapidly increases to the value greater than $70^{\circ}$. However, when the bias power continued to increase, the sidewall angle will decrease slowly. The physical etching mechanism plays an important role in the change of the trend. In the chamber, some particles move at the direction perpendicular to the sample surface, while the others moving at an oblique direction. When the bias power lower than $80 \mathrm{~W}$, with increasing bias power, the vertical etching becomes the dominating mechanism. Therefore, the sidewall angle increases rapidly. When the bias power is up to 
$80 \mathrm{~W}$, with the further increase, the effect of oblique etching becomes obvious. Hence, the sidewall angle gradually decreases.

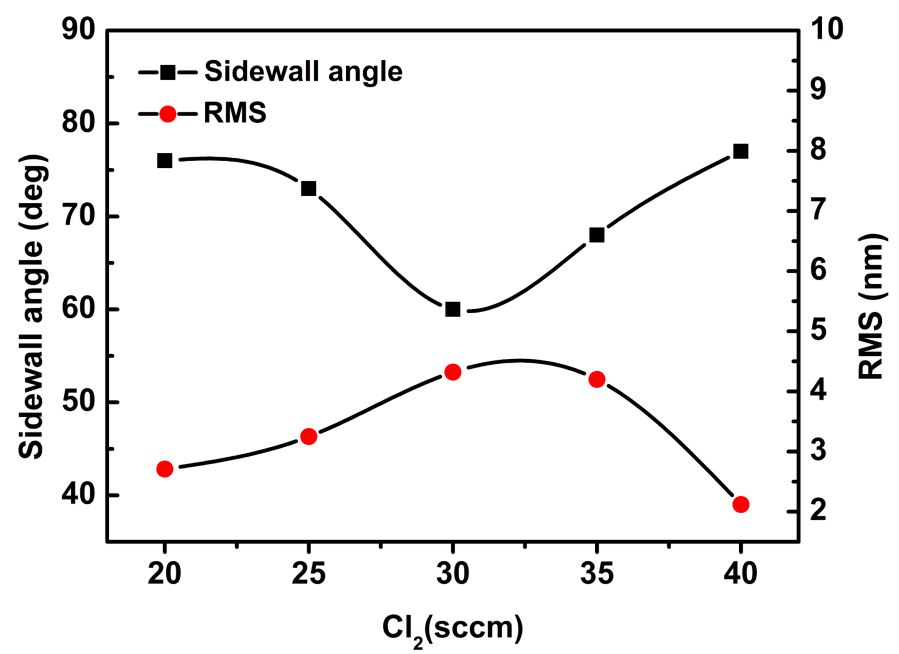

Figure 5. Sidewall angle and root-mean-square (RMS) versus the flow rate of $\mathrm{Cl}_{2}$.

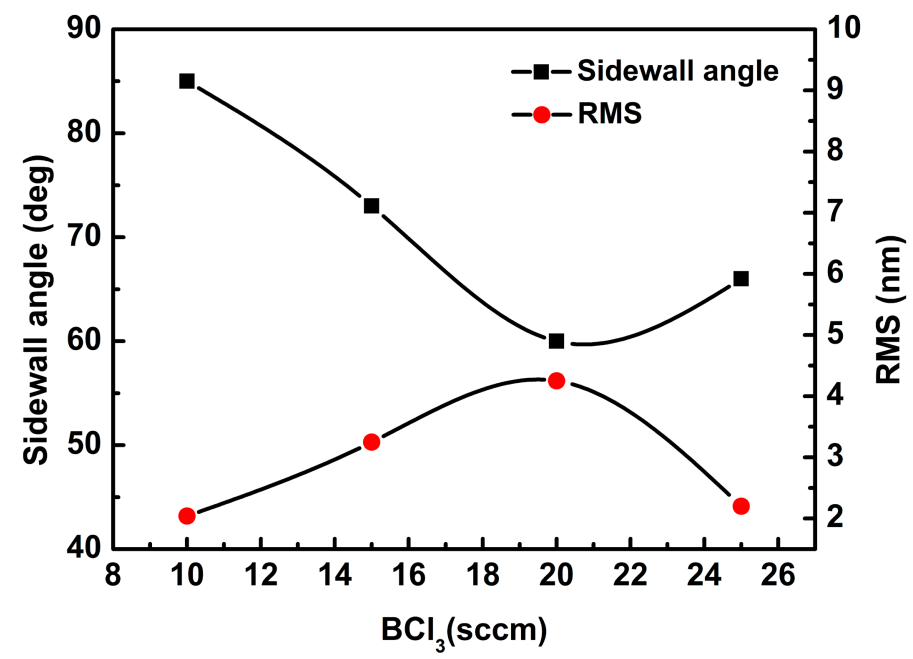

Figure 6. Sidewall angle and RMS versus the flow rate of $\mathrm{BCl}_{3}$.

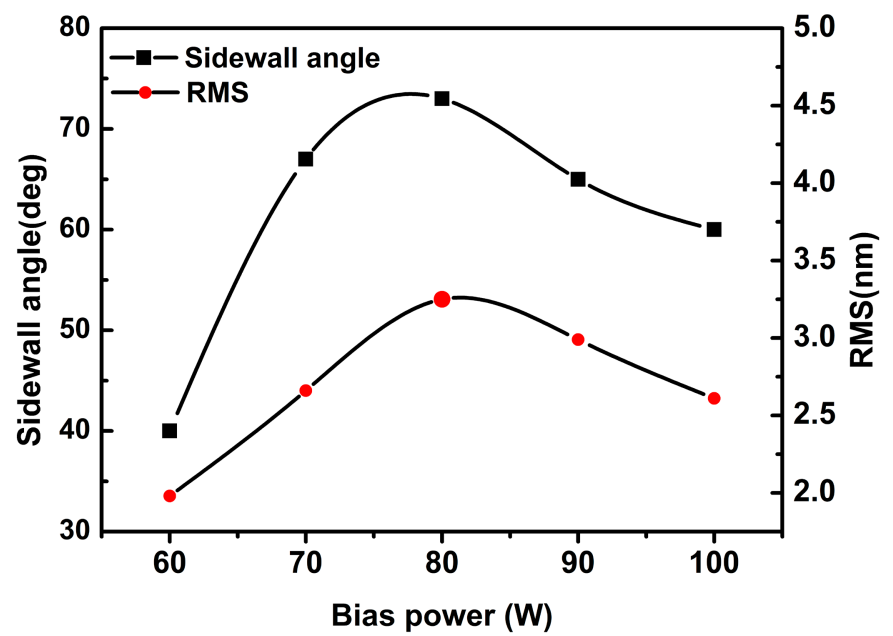

Figure 7. Sidewall angle and RMS versus the bias power. 
The surface roughness shows the same trend with sidewall angle as shown in Figure 7. With the bias power increased, the difference of the etching rates between the grain boundaries and the inside grains will be enlarged. Therefore, the surface roughness will increase rapidly. The etching rates will be raised when the bias power is further increased. However, the difference will be decreased. Hence, the roughness decreases slowly. It is the same with the trend of RMS versus $\mathrm{Cl}_{2}$ or $\mathrm{BCl}_{3}$, as shown in Figures 5 and 6 .

The sidewall angle increases linearly with the increase of the flow rate of Ar, as shown in Figure 8. In the etching system, Ar acts as the bombardment particle. The physical bombardment etching is anisotropic. Therefore, the higher the flow rate of Ar, the higher the sidewall angle.

Figure 9 shows the sidewall angle as a function of the chamber pressure. The sidewall angle hovers around $70^{\circ}$ with the pressure increased from 0.5 to $2 \mathrm{~Pa}$.

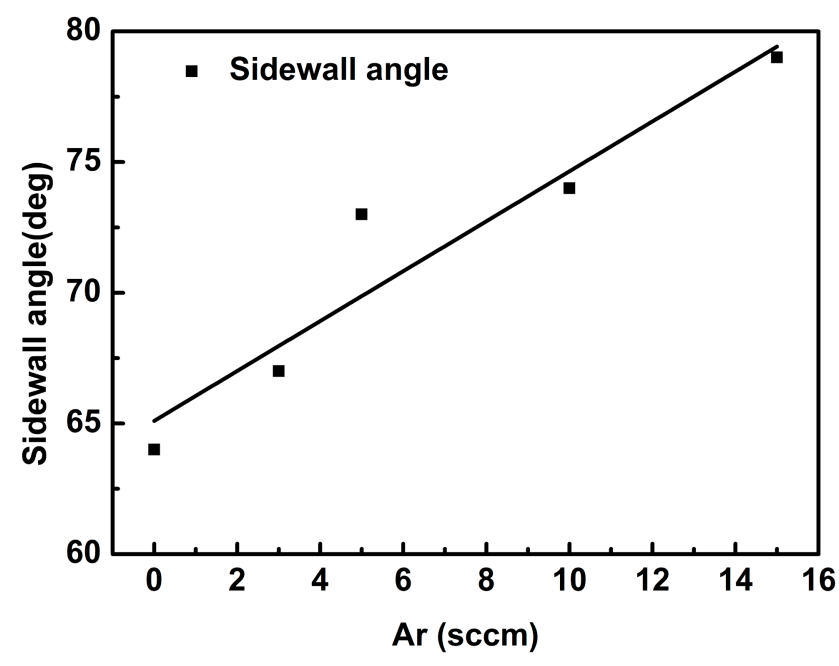

Figure 8. Sidewall angle versus the flow rate of Ar.

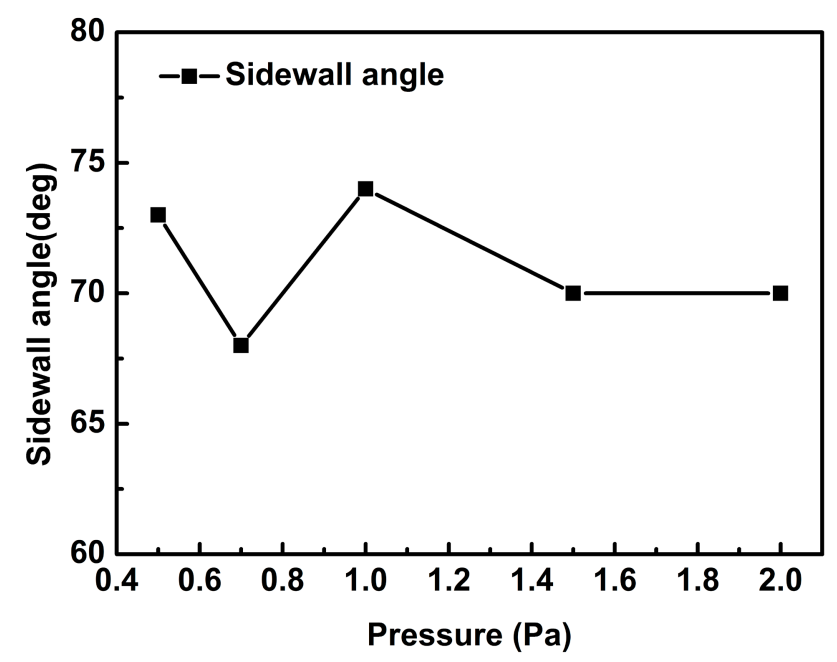

Figure 9. Sidewall angle versus the pressure.

\subsection{Microtrenching Effect and the Bottom Electrode}

Figure 10 shows the etching results which were measured by SEM. The values of the thickness, height and angle are shown in it. From this figure, no obvious microtrenching effect can be seen. Figure 11 shows the bottom roughness of the etching area measured by AFM. The value of RMS is $1.98 \mathrm{~nm}$. 

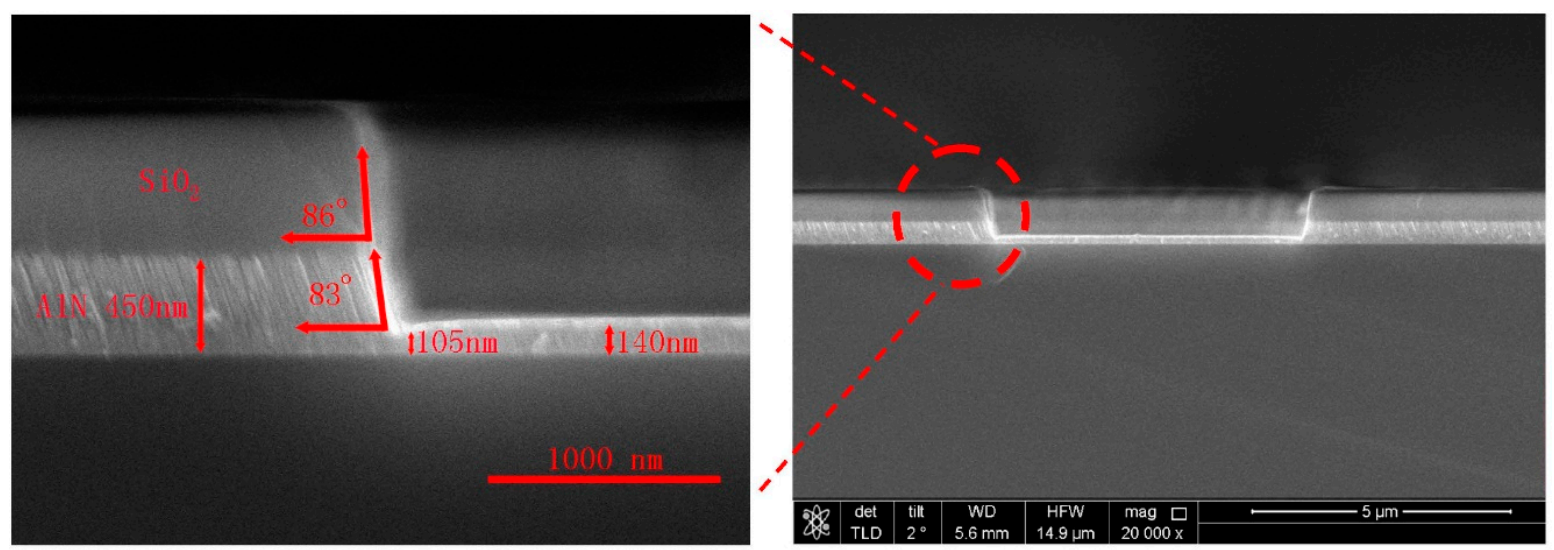

Figure 10. SEM cross-section images of AlN etching.

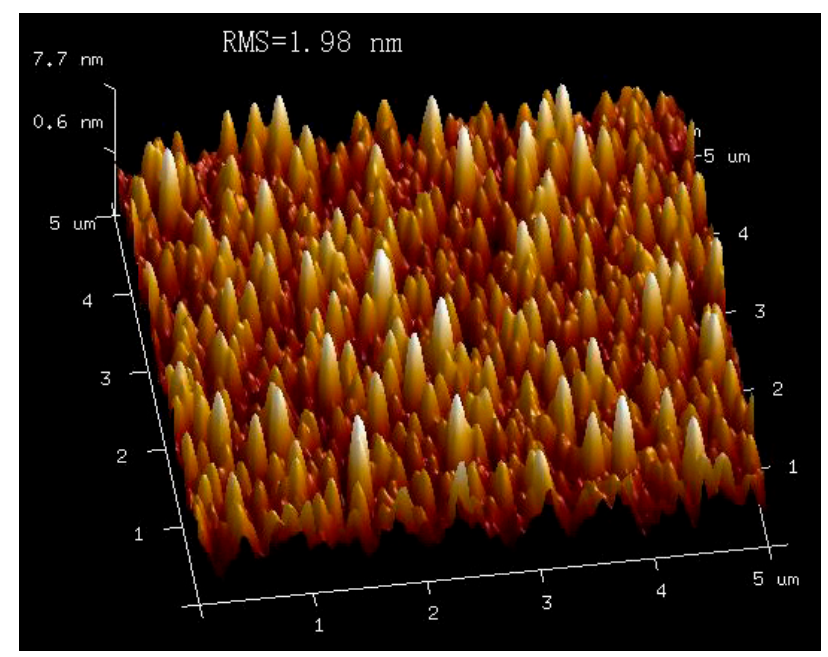

Figure 11. The bottom surface roughness of AlN etching measured by AFM.

In the microtrenching effect, the etching rate of the bottom corner is faster than the center. Hence, there will be a small trench at the bottom corner. To indicate the microtrenching effect, a formula can be used as follows [7]:

$$
M=\frac{d_{s}-d_{c}}{d_{c}} \times 100 \%
$$

where $d_{\mathrm{s}}$ represents the etching depth of the corners and $d_{\mathrm{c}}$ is that of the center. The higher the value of $M$, the more serious the microtrenching effect. In this experiment, a near vertical etching process is achieved. The value of $M$ is $11.3 \%$. This means the microtrenching effect is not obvious. The sidewall angle of AlN is $83^{\circ}$. The cross section view can be seen in Figure 10. The parameters of this vertical etching recipe are as follow. The $\mathrm{Cl}_{2} / \mathrm{BCl}_{3} / \mathrm{Ar}$ flow rates are $25 / 10 / 5 \mathrm{sccm}$ respectively. Other parameters are the same as the initial process.

In the contour mode AlN resonator, the common bottom electrode is $\mathrm{Pt} / \mathrm{Ti}$ [13]. Ti is used as an adhesive layer between the silicon substrate and the Pt layer. Compared with other metal materials, $\mathrm{Pt}$ has a low lattice and thermal expansion coefficient mismatches with (002)-orientated AIN. In the etching process, the Pt electrode acts as a stop layer due to the high selectivity of AlN/Pt. In the vertical etching recipe mentioned above, the selectivity of AlN/Pt is 3:1. The etching rate of AlN is $77.5 \mathrm{~nm} / \mathrm{min}$, while 
that of $\mathrm{Pt}$ is $25.5 \mathrm{~nm} / \mathrm{min}$. The physical bombardment etching plays a major role in the Pt etching. Hence, the etching rate of $\mathrm{Pt}$ is low. This stop layer can also solve the etching depth uniformity issues in the different size patterns effectively.

\section{Conclusions}

This paper focused on AIN ICP etching process. In this experiment, $\mathrm{Cl}_{2} / \mathrm{BCl}_{3} / \mathrm{Ar}$ was used as the basic etching gases. The etching parameters of gases flow rate, chamber pressure and bias power were adjusted. As a result, a sidewall angle of $83^{\circ}$, M value of $11.3 \%$ and RMS value of $1.98 \mathrm{~nm}$ were achieved. The selectivity of AlN/Pt is 3:1. The Pt layer plays an important role as the stop-layer. This etching result can meet the manufacturing requirements of AIN MEMS resonators.

\section{Acknowledgments}

The authors gratefully acknowledge Chinese National Science Foundation (Contract No. 61274001, and No. 61234007) and the Nurturing and Development Special Projects of Beijing Science and Technology Innovation Base's financial support (Contract No. Z131103002813070).

\section{Author Contributions}

Jian Yang, Chaowei Si, Guowei Han, Meng Zhang, Liuhong Ma, Yongmei Zhao and Jin Ning conceived and designed the experiments; Jian Yang, Meng Zhang and Jin Ning performed the experiments; Jian Yang and Jin Ning analyzed the data; Jian Yang wrote the paper; Jian Yang, Liuhong Ma and Jin Ning revised the paper. All authors read and approved the final manuscript.

\section{Conflicts of Interest}

The authors declare no conflict of interest.

\section{References}

1. Sanchez-Rojas, J.-L.; Hernando, J.; Ababneh, A.; Schmid, U.; Olivares, J.; Clement, M.; Iborra, E. Advanced determination of piezoelectric properties of AlN thin films on silicon substrates. In Proceedings of IEEE Ultrasonics Symposium, Beijing, China, 2-5 November 2008; pp. 903-906.

2. Wang, S.; Xu, Y.; Zheng, S.; Han, D. Development of $1.8 \mathrm{GHz}$ film bulk acoustic resonator based on AlN. J. Artic. Semiconduct. Technol. 2012, 37, 146-149.

3. Rinaldi, M.; Zuniga, C.; Piazza, G. 5-10 GHz AlN contour-mode nanoelectromechanical resonators, In Proceedings of IEEE 22nd International Conference on Micro Electro Mechanical Systems, Sorrento , Italy, 25-29 January 2009; pp. 916-919.

4. Lin, C.M.; Chen, Y.Y.; Felmetsger, V.V.; Senesky, D.G.; Pisano, A.P. AlN/3C-SiC composite plate enabling high-frequency and high-Q micromechanical resonators. Adv. Mater. 2012, 24, 2722-2727.

5. Lin, C.M.; Yantchev, V.; Zou, J.; Chen, Y.Y.; Pisano, A.P. Micromachined one-port aluminum nitride lamb wave resonators utilizing the lowest-order symmetric mode. J. Microelectromech. Syst. 2014, 23, 78-91. 
6. Lin, C.M.; Yen, T.T.; Lai, Y.J.; Felmetsger, V.V.; Hopcroft, M.A.; Kuypers, J.H.; Pisano, A.P. Temperature-compensated aluminum nitride lamb wave resonators. IEEE Trans. Ultrason. Ferroelectr. Freq. Control 2010, 57, 524-532.

7. Bliznetsov, V.; Bin Johari, B.H.; Chentir, M.T.; Li, W.H.; Wong, L.Y.; Merugu, S.; Zhang, X.L.; Singh, N. Improving aluminum nitride plasma etch process for MEMS applications. J. Micromech. Microeng. 2013, 23, 117001.

8. Hahn, Y.; Hays, D.; Donovan, S.; Abernathy, C.; Han, J.; Shul, R.; Cho, H.; Jung, K.; Pearton, S. Effect of additive noble gases in chlorine-based inductively coupled plasma etching of $\mathrm{GaN}$, InN, and AlN. J. Vac. Sci. Technol. A 1999, 17, 768-773.

9. Khan, F.; Zhou, L.; Kumar, V.; Adesida, I.; Okojie, R. High rate etching of AlN using $\mathrm{BCl}_{3} / \mathrm{Cl}_{2} / \mathrm{Ar}$ inductively coupled plasma. Mater. Sci. Eng. B 2002, 95, 51-54.

10. Shah, A.P.; Laskar, M.R.; Rahman, A.A.; Gokhale, M.R.; Bhattacharya, A. Inductively coupled plasma reactive ion etching of III-nitride semiconductors. Solid State Phys. 2013, 1512, 494-495.

11. Shah, A.P.; Laskar, M.R.; Rahman, A.A.; Gokhale, M.R.; Bhattacharya, A. Inductively coupled plasma-reactive ion etching of c-and a-plane AlGaN over the entire $\mathrm{Al}$ composition range: Effect of $\mathrm{BCl}_{3}$ pretreatment in $\mathrm{Cl}_{2}$ /Ar plasma chemistry. J. Vac. Sci. Technol. A 2013, 31, 061305.

12. Shul, R.; Willison, C.; Bridges, M.; Han, J.; Lee, J.; Pearton, S.; Abernathy, C.; MacKenzie, J.; Donovan, S.; Zhang, L. Selective inductively coupled plasma etching of group-III nitrides in $\mathrm{Cl}_{2}$ and $\mathrm{BCl}_{3}$ based plasmas. J. Vac. Sci. Technol. A 1998, 16, 1621-1626.

13. Xiong, J.; Gu, H.-S.; Hu, K.; Hu, M.-Z. Influence of substrate metals on the crystal growth of AlN films. Int. J. Miner. Metall. Mater. 2010, 17, 98-103.

(C) 2015 by the authors; licensee MDPI, Basel, Switzerland. This article is an open access article distributed under the terms and conditions of the Creative Commons Attribution license (http://creativecommons.org/licenses/by/4.0/). 